\title{
Mitochondrial Acetoacetyl-CoA Thiolase (T2) Deficiency: T2-Deficient Patients with "Mild" Mutation(s) Were Previously Misinterpreted as Normal by the Coupled Assay with Tiglyl-CoA
}

\author{
GAI XIU ZHANG, TOSHIYUKI FUKAO, MARIE-ODILE ROLLAND, MARIE-THERESE ZABOT, \\ GILLES RENOM, ELIAS TOUMA, MASASHI KONDO, NAOKI MATSUO, AND NAOMI KONDO
}

\begin{abstract}
Department of Pediatrics [G.X.Z., T.F., M.K., N.M., N.K.], Graduate School of Medicine, Gifu University, Gifu, Gifu 501-1194, Japan; Service de Biochimie Pediatrique [M.-O.R.], Hopital Debrousse, 69322 Lyon Cedex 05, France; Centre de Biotechnologie Cellulaire [M.-T.Z.], Hopital Debrousse, 69322 Lyon Cedex 05, France; Laboratoire de Biochimie et de Biologie Moléculaire [G.R.], Hopital Claude Huriez, CHRU, 59037 Lille Cedex, France; and The Center for Reproductive Medicine and Genetics [E.T.], Abou-Jaoude Hospital, Jal-eldib, Lebanon
\end{abstract}

\begin{abstract}
Mitochondrial acetoacetyl-CoA thiolase (T2) deficiency is an inborn error of metabolism that affects the catabolism of isoleucine and ketone bodies. This disorder is characterized by intermittent ketoacidotic episodes. Recently, we diagnosed T2 deficiency in two patients (GK45 and GK47) by the absence of potassium ion-activated acetoacetyl-CoA thiolase activity, whereas these patients were previously misinterpreted as normal by a coupled assay with tiglyl-CoA as a substrate. This method has been widely used for the enzymatic diagnosis of the T2 deficiency in the United States and Europe. We hypothesized that some residual T2 activity showed normal results in the assay. To prove this hypothesis, we analyzed these two patients together with three typical T2-deficient patients (GK46, GK49, and
\end{abstract}

\section{ABSTRACT}

GK50) at the DNA level. Expression analysis of mutant cDNAs clearly showed that GK45 and GK47 had "mild" mutations (A132G, D339-V340insD) that retained some residual T2 activity, at least one of two mutant alleles, whereas the other three patients had null mutations (c.52-53insC, G152A, H397D, and IVS $8+1 g>t$ ) in either allele. These results raise the possibility that T2-deficient patients with mild mutations have been misinterpreted as normal by the coupled assay with tiglyl-CoA. (Pediatr Res 56: 60-64, 2004)

\section{Abbreviations}

SCOT, succinyl-CoA: 3-oxoacid CoA transferase T2, mitochondrial acetoacetyl-CoA thiolase
Mitochondrial acetoacetyl-CoA thiolase (T2; EC 2.3.1.9) deficiency is an autosomal recessive disorder that affects the catabolism of isoleucine and ketone bodies $(1,2)$. This disorder, commonly known as the $\beta$-ketothiolase deficiency (McKusick catalogue no. 203750), is characterized by intermittent ketoacidotic episodes. The urinary organic acid profiles of T2 deficiency are typically characterized by massive excretion of tiglylglycine, 2-methyl-3-hydroxybutyrate, and 2-methylacetoacetate in both ketoacidotic and stable conditions $(2,3)$. We previously carried out mutation analysis on 26 patients and evaluated missense mutations by transient expression analysis of the mutant cDNAs (3). On the basis of the residual T2

Received July 9, 2003; accepted October 29, 2003.

Correspondence: Toshiyuki Fukao, M.D., Ph.D., Gifu University, 1-1 Yanagido, Gifu, Gifu 501-1194, Japan; e-mail: toshi-gif@umin.ac.jp

Supported in part by a Grant-in-Aid for Scientific Research (09770540) from the Ministry of Education, Science, Technology, Sports and Culture of Japan.

DOI: 10.1203/01.PDR.0000129657.48122.52 activity in the expression analysis of mutant cDNAs, we divided T2-deficient patients into two groups: patients with null mutations in either allele (patients with "severe" mutations) and patients with mutation(s) that retain some residual T2 activity in at least one of two mutant alleles (patients with "mild" mutations). We found no apparent correlation between clinical severity and genotype (3). However, 7 of the 26 did not excrete any detectable amount of tiglylglycine even during ketoacidotic episodes, and, at that time, 6 of the 7 had mild mutations. We recently showed that urinary organic acid and acylcarnitine profiles during nonepisodic conditions were different between patients with mild mutations and those with severe mutations (4). Hence, there is a clear correlation between biochemical phenotype and genotype.

We recently diagnosed T2 deficiency in two patients who were previously misinterpreted as normal by the coupled assay with tiglyl-CoA (5). We hypothesized that the presence of residual $\mathrm{T} 2$ activity in cells from these patients might lead to a 
normal result in this assay and that T2-deficient patients with mild mutation(s) had been incorrectly interpreted as normal by the coupled assay. We herein analyzed these two patients together with three typical T2-deficient patients at the molecular level to prove the hypothesis.

\section{METHODS}

Patients. Brief clinical descriptions for all of the patients are as follows. GK45 is an Armenian boy who was born to consanguineous parents. He experienced the first ketoacidotic episode at the age of 15 mo. Blood $\mathrm{pH}$ was 7.2, with $\mathrm{PCO}_{2}$ of $13 \mathrm{~mm} \mathrm{Hg}$ and $\mathrm{HCO}_{3}{ }^{-}$of $4 \mathrm{mM}$. After he obtained i.v. fluids, he recovered promptly. However, another severe episode occurred $20 \mathrm{~d}$ later. Urinary organic acid analysis during the crisis revealed the presence of 2-methyl-3-hydroxybutyrate and 2-methylacetoacetate but no tiglylglycine. He was put on a moderate protein-restricted diet $\left(2 \mathrm{~g} \cdot \mathrm{kg}^{-1} \cdot \mathrm{d}^{-1}\right)$. He had no further crises and developed normally. One of us performed the coupled assay with tiglyl-CoA, which revealed normal T2 activity. Then the fibroblasts were analyzed again in Gifu University School of Medicine by potassium ion-activated acetoacetyl-CoA thiolase activity and revealed T2 deficiency.

GK46 was a boy who was born to nonconsanguineous Vietnamese parents in France. He was well until 18 mo of age, when he developed a ketoacidotic episode. Blood gas data in the episode was as follows: $\mathrm{pH} 6.92, \mathrm{PCO}_{2} 10 \mathrm{~mm} \mathrm{Hg}, \mathrm{HCO}_{3}{ }^{-}$ $2 \mathrm{mM}$. At that time, urinary organic acid analysis showed massive excretion of tiglylglycine and 2-methyl-3-hydroxybutyrate. He recovered after fluid therapy. He was put on a low-protein diet for only $1.5 \mathrm{y}$. He never had another ketoacidotic episode, but urinary organic acid analysis revealed massive excretion of tiglylglycine and 2-methyl-3-hydroxybutyrate when he was clinically normal. His growth and development are within the normal range.

GK47's case report has been published as a curious case. He is a boy who was born to unrelated white parents and was clinically suspected of having T2 deficiency but normal activity in the coupled assay with tiglyl-CoA (6). He experienced two severe ketoacidotic episodes at the ages of 19 mo and 49 mo. During the first crisis, blood pH was 6.97, with $\mathrm{PCO}_{2}$ of $10.5 \mathrm{~mm} \mathrm{Hg}$ and $\mathrm{HCO}_{3}{ }^{-}$of $2.3 \mathrm{mM}$. Clinical improvement was obtained by i.v. fluid therapy. Nine months later, he was hospitalized for mental disorientation and speech difficulties. Urinary acylcarnitine analysis showed the presence of tiglylcarnitine and 2-methyl-3-hydroxybutyrylcarnitine. Treatment with L-carnitine $\left(3 \times 25 \mathrm{mg} \cdot \mathrm{kg}^{-1} \cdot \mathrm{d}^{-1}\right)$ was administered without any particular low-protein diet and avoided prolonged fasting. He has subsequently been healthy but still excretes tiglylcarnitine and 2-methyl-3-hydroxybutyrylcarnitine in his urine.

GK49 was a boy of consanguineous parents. He experienced the ketoacidotic episode at the age of $15 \mathrm{mo}$. Blood gas $\mathrm{pH}$ was 6.5. Analysis of acylcarnitine in the urine showed the presence of tiglylcarnitine and 2-methyl-3-hydroxybutyrylcarnitine. Clinical improvement took place when he was put on i.v. fluids and a moderately protein-restricted diet. He experienced no further crisis and developed normally.
GK50 is a boy of nonconsanguineous parents. He experienced a ketoacidotic episode at the age of $2 \mathrm{~d}$ with polypnea and hypotonia. The blood $\mathrm{pH}$ was 7.2 , and the anion gap was 35 . Urinary organic analysis revealed the presence of tiglylglycine, 2-methyl-3-hydroxybutyrate, and 2-methylacetoacetate. After correcting $\mathrm{pH}$ with i.v. fluids, prompt recovery was obtained and milk was reintroduced into his diet at day 4. His development is within the normal range.

Fibroblasts. Informed consent was obtained from the patients' parents to perform skin biopsy, enzyme assay, and molecular analyses. This study was approved by the review board of Gifu University School of Medicine.

Fibroblasts from GK45, GK46, GK47, GK49, and GK50 were grown in Eagle's minimal essential medium that contained $10 \%$ FCS.

Enzyme assay and immunoblot analysis. T2 activity was measured as potassium ion-activated acetoacetyl-CoA thiolase activity as described (7). The coupled assay with tiglyl-CoA as a substrate was done according to Gibson et al. (5). Immunoblot analysis was performed with a mixture of an anti-T2 antibody and anti-succinyl-CoA:3-oxoacid CoA transferase (SCOT) antibody as the first antibody. SCOT protein served as positive control (8).

Mutation detection. RNA was isolated using ISOGEN kits according to the manufacturer's instructions (Nippon Gene, Tokyo, Japan). Genomic DNA was prepared using Sepa gene kits (Sanko Junyaku, Tokyo, Japan) from fibroblasts. The oligonucleotide primers for cDNA synthesis and PCR amplification of T2 cDNA were described previously (9). The PCR fragments were extracted, subcloned, and sequenced as described (9). Mutations were confirmed by direct sequencing of amplified genomic fragments (8).

Transient expression analysis. Transient expression analysis of T2 cDNAs was done using a pCAGGS eukaryote expression vector $(10)$ as described $(11,12)$. The expression constructs were transfected into SV40-transformed T2deficient fibroblast cell lines (GK03) with Lipofectamine 2000 (Invitrogen, San Diego, CA, U.S.A.). After transfection, the cells were further cultured at either $37^{\circ} \mathrm{C}$ or $30^{\circ} \mathrm{C}$ for $72 \mathrm{~h}$, and then they were harvested. The cells were freeze-thawed and sonicated in $50 \mathrm{mM}$ sodium phosphate $(\mathrm{pH} 8.0)$ and $0.1 \%$ Triton X-100. After centrifugation at $10,000 \times g$ for $10 \mathrm{~min}$, the supernatants were used for enzyme assay and for immunoblot analysis. Heat instability for enzyme activity was tested using $30^{\circ} \mathrm{C}$ expression samples, as described $(8,13)$.

\section{RESULTS}

Enzyme assay and immunoblot analysis. As shown in Table 1 , enzyme assay data using the coupled assay with tiglyl-CoA were within the normal range in fibroblasts from GK45 and GK47, whereas potassium ion-activated acetoacetyl-CoA thiolase activity was hardly detected in the fibroblasts from all the patients. Immunoblot analysis using $30 \mu \mathrm{g}$ of protein showed that $\mathrm{T} 2$ protein was hardly detected in fibroblasts from all five patients, but the $\mathrm{T} 2$ protein in the control fibroblast was clearly detected even when $3.7 \mu \mathrm{g}$ of protein was applied to SDS- 
Table 1. Enzyme assays in fibroblasts

\begin{tabular}{|c|c|c|c|c|c|}
\hline \multirow[b]{2}{*}{ Case } & \multirow{2}{*}{$\begin{array}{c}\text { Coupled assay } \\
\text { with tiglyl-CoA }\end{array}$} & \multicolumn{3}{|c|}{ Acetoacetyl-CoA thiolase } & \multirow[b]{2}{*}{ SCOT } \\
\hline & & $-\mathrm{K}^{+}$ & $+\mathrm{K}^{+}$ & $+\mathrm{K}^{+} /-\mathrm{K}^{+}$ & \\
\hline GK45 & 35 & $2.7 \pm 0.1$ & $3.0 \pm 0.1$ & $1.1 \pm 0.1$ & $4.2 \pm 0.1$ \\
\hline GK47 & 23 & $4.3 \pm 0.8$ & $5.2 \pm 1.0$ & $1.2 \pm 0.1$ & $6.5 \pm 4.1$ \\
\hline GK49 & 1.8 & 5.3 & 5.5 & 1.0 & 6.7 \\
\hline GK50 & 0 & 4.2 & 5.5 & 1.3 & 4.6 \\
\hline
\end{tabular}

In the cases of GK45 and GK47, acetoacetyl-CoA thiolase and SCOT activities were assayed three times and the average and SDs are shown.

PAGE (Fig. 1). These data confirmed that all five patients had the $\mathrm{T} 2$ deficiency.

Mutations in the five patients. We amplified the entire coding region of T2 cDNA in all five patients. Mutations were screened at the cDNA level first after subcloning RT-PCR fragments and then confirmed at the genomic level by direct sequencing. We found six mutations in the five T2-deficient patients. GK45 was a homozygote of c.395C $>$ G (A132G). GK46 was a compound heterozygote of c.52-53insC and c. $455 \mathrm{G}>\mathrm{C}$ (G152A). GK47 was also a compound heterozygote of G152A and c.1018-1019insATG (D339-V340insD). GK49 and GK50 were homozygotes of c.1189C $>$ G (H397D) and IVS8 $+1 \mathrm{~g}>\mathrm{t}$, respectively. C.52-53insC causes a reading frame shift and produces a premature termination. IVS $8+1 \mathrm{~g}>\mathrm{t}$ causes exon 8 skipping and was proved to produce no T2 protein in the previous study (9). To confirm the other mutations as being causative mutations, we performed a transient expression analysis of mutant cDNAs.

Transient expression analysis of mutant cDNAs. Transient expression of mutant cDNAs (A132G, D339-V340insD, G152A, and H397D) was done with a mild mutant (T297M) as a positive mutant for retaining significant residual T2 activity (14). After expression of cDNAs in the recipient T2-deficient cells for $72 \mathrm{~h}$ at $37^{\circ} \mathrm{C}$ and $30^{\circ} \mathrm{C}$, enzyme assays and immunoblots were done (Fig. 2). In the case of the transfection of wild-type T2 cDNA, T2 activity in the expression at $30^{\circ} \mathrm{C}$ was higher than that in the expression at $37^{\circ} \mathrm{C}$. This temperaturesensitive character was more evident in the transfection of mutant cDNAs. A132G and D339-V340insD mutant T2 cDNAs retained $10 \%$ residual $\mathrm{T} 2$ activity in the expression at $37^{\circ} \mathrm{C}$ and higher residual activity in the expression at $30^{\circ} \mathrm{C}$. D339-V340insD mutant T2 protein migrated slower than the

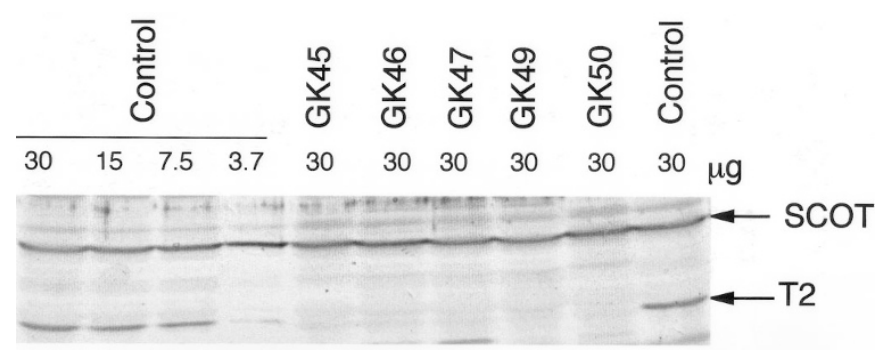

Figure 1. Immunoblot analysis in fibroblasts. A mixture of anti-T2 and anti-SCOT antibodies was used as the first antibody. Positions of SCOT and T2 are indicated with arrows. Thirty micrograms of protein was applied in the lanes of patients. In the lanes of the control, 2-fold serially diluted samples were applied, as indicated above the lanes. wild $\mathrm{T} 2$ protein on the $10 \%$ polyacrylamide gel. The G152A mutant retained $\sim 5 \%$ of residual activity only in the expression at $30^{\circ} \mathrm{C}$. Mutant $\mathrm{H} 397 \mathrm{D}$ retained no residual $\mathrm{T} 2$ activity in the expression at either $37^{\circ} \mathrm{C}$ or $30^{\circ} \mathrm{C}$. In immunoblot analysis, the amount of mutant $\mathrm{T} 2$ protein was estimated by comparison with 2-fold serial diluted samples of wild-type T2. In mock cDNA transfection, $\mathrm{T} 2$ protein was not detected in the expression at either $37^{\circ} \mathrm{C}$ or $30^{\circ} \mathrm{C}$. In the expression of $\mathrm{A} 132 \mathrm{G}$ and D339-V340insD mutant cDNAs, mutant proteins were detected and the accumulation of these mutant proteins was temperature sensitive. In the case of G152A, mutant protein was faintly detected in the expression at $37^{\circ} \mathrm{C}$, but $\mathrm{T} 2$ protein was clearly detected in the expression at $30^{\circ} \mathrm{C}(\sim 15 \%$ of control). The H397D mutant protein was not detected even in the expression at $30^{\circ} \mathrm{C}$. The heat stability for the enzyme activity of A132G, G152A, and D339-V340insD mutant proteins was almost the same as that of wild-type T2 protein (data not shown).

\section{DISCUSSION}

In this article, we presented two T2-deficient patients (GK45 and GK47) whose fibroblasts showed normal activity in the coupled assay with tiglyl-CoA but defective potassium ionactivated acetoacetyl-CoA thiolase activity for the first time. We confirmed T2 defects in GK45 and GK47 in immunoblot analysis followed by mutation analysis. The coupled assay was first described in 1992 (5) and had been used to diagnose T2-deficient patients until 2001 in the United States and Europe. GK47 was previously reported as a curious case whose clinical presentation, including biochemical phenotype, accorded with T2 deficiency but had normal enzyme activity using the coupled assay (6). As shown in the case reports, there is no apparent clinical difference between these two patients and the other patients.

Three enzyme assays have been used for the diagnosis of the T2 deficiency $(5,7,15)$. Potassium ion-activated acetoacetylCoA thiolase activity (7) and 2-methylacetoacetyl-CoA thiolase activity are specific for T2 activity (15), but the coupled assay examines the pathway of isoleucine catabolism from tiglyl-CoA to methylmalonyl-CoA (5). Hence, a defect in tiglyl-CoA hydratase, 2-methyl-3-hydroxybutyryl-CoA dehydrogenase, T2, or propionyl-CoA carboxylase is theoretically detectable. If any of these enzymes is completely defective, then the total activity measured by the assay is expected to be very low. However, it is possible that some residual enzyme 

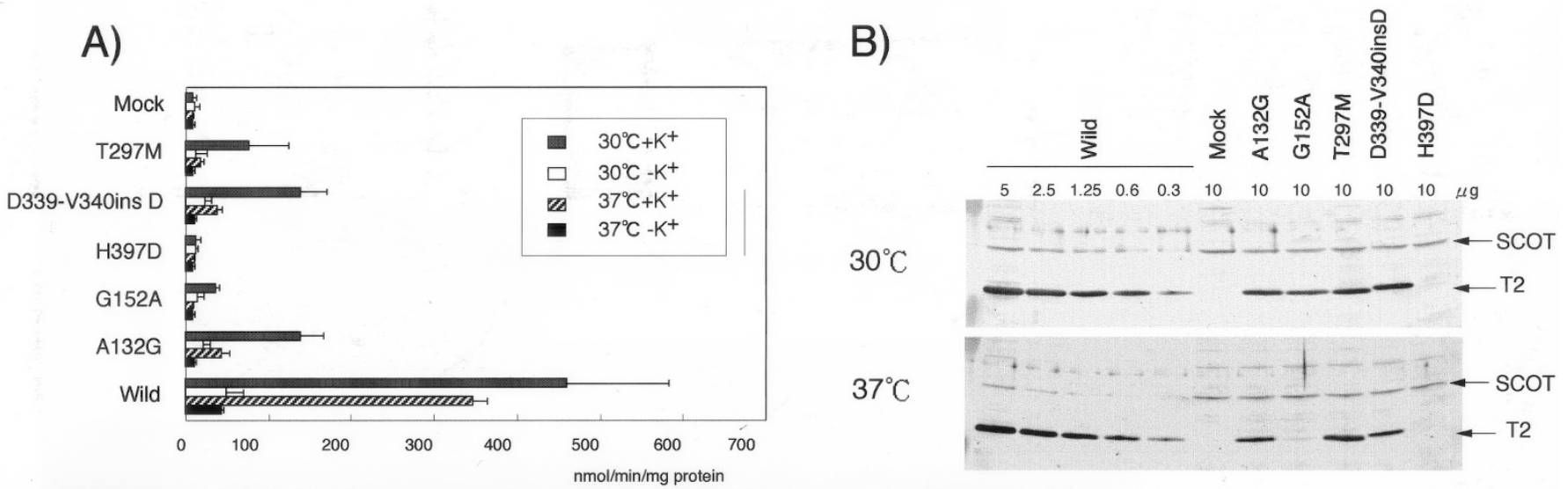

Figure 2. Transient expression analysis of mutant cDNAs. Transient expression analyses were done at both $37^{\circ} \mathrm{C}$ and $30^{\circ} \mathrm{C}$. The $\mathrm{T} 297 \mathrm{M}$ mutant is a positive control that retained some residual T2 activity. (A) Potassium ion-activated acetoacetyl-CoA thiolase assay. Acetoacetyl-CoA thiolase activity in the supernatant of the cell extract was measured. The mean values of acetoacetyl-CoA thiolase activity in the absence and presence of potassium ions are shown together with the SD of four experiments. $(B)$ Immunoblot analysis. Protein amounts applied are shown above the lanes. A mixture of anti-rat T2 antibody and anti-human SCOT antibody was used as the first antibody

activity in one of them is enough to present normal enzyme activity in the coupled assay.

We clearly proved our hypothesis that some residual T2 activity shows normal results in the coupled assay with tiglylCoA. We demonstrated by mutation analysis followed by transient expression analysis of mutant cDNAs that A132G and D339-V340insD retained $\sim 10 \%$ of the residual T2 activity in the expression at $37^{\circ} \mathrm{C}$. Because GK45 is a homozygote of A132G and GK47 is a compound heterozygote of D339V340insD and G152A, their fibroblasts are expected to have $\sim 10$ and $5 \%$ residual activities, respectively. However, none of the mutations (c.52-53insC, G152A, H397D, and IVS8+1g>t) identified in the other three T2-deficient patients retained any residual activity in the expression at $37^{\circ} \mathrm{C}$. These findings have good correlation with the fact that GK45 and GK47 had normal activity and the others were defective in the coupled assay with tiglyl-CoA.

Our findings are supported by the findings in another paper (5). One patient with the T2 deficiency (L.V.; our laboratory number GK03) was reported to have exceptionally high activity $\left(8.7 \pm 3.7 \mathrm{pmol} \cdot \mathrm{min}^{-1} \cdot \mathrm{mg}\right.$ protein ${ }^{-1}$; control values 32 $\pm 23 \mathrm{pmol} \cdot \min ^{-1} \cdot \mathrm{mg}$ protein $\left.{ }^{-1}\right)$ compared with other T2-deficient patients $\left(0.7 \pm 0.5 \mathrm{pmol} \cdot \mathrm{min}^{-1} \cdot \mathrm{mg}_{\text {protein }}{ }^{-1}\right)$ in this assay (5). Middleton et al. $(15,16)$ reported that GK03's fibroblasts have low but significant residual T2 activity (6.6 $\mathrm{nmol} \cdot \min ^{-1} \cdot \mathrm{mg}$ protein ${ }^{-1}$; control values $89 \pm 11 \mathrm{nmol}$. $\min ^{-1} \cdot \mathrm{mg}$ protein ${ }^{-1}$; typical T2-deficient fibroblasts $<4.0$ $\mathrm{nmol} \cdot \min ^{-1} \cdot \operatorname{mg}$ protein ${ }^{-1}$ ), using the $\mathrm{T} 2$ specific assay with 2-methylacetoacetyl-CoA. Taken together, even very low residual $\mathrm{T} 2$ activity may result in much higher residual activity in the coupled assay using tiglyl-CoA.

Among the five patients studied in this article, GK45 and GK47 can be subgrouped into patients with mild mutations and the others with severe mutations. We divided T2-deficient patients into two groups on the basis of the residual T2 activity in the expression analysis of mutant cDNAs $(3,4)$ - patients with null mutations in either allele (patients with severe mutations) and patients with mutation(s) that retain some residual
T2 activity in at least one of two mutant alleles (patients with mild mutations) - and compared several aspects of these groups. The biochemical phenotype, such as blood acylcarnitine and urinary organic acid profiles in a nonepisodic condition, is different between the two groups $(3,4)$. However, present and previous studies showed that T2-deficient patients with mild mutations do not differ from those with severe mutations in 1) the severity of ketoacidotic crises, 2) frequency of ketoacidotic crises, and 3) prognosis. Hence, it is very important to diagnose $\mathrm{T} 2$ deficiency with mild mutations properly. Our results raised the possibility that T2-deficient patients with mild mutations had been misinterpreted as normal by the coupled assay with tiglyl-CoA.

Acknowledgments. We thank N. Sakaguchi for technical assistance.

\section{REFERENCES}

1. Daum RS, Lamm PH, Mamer OA, Scriver CR 1971 A "new" disorder of isoleucine catabolism. Lancet 2:1289-1290

2. Mitchell GA, Fukao T 2001 Inborn errors of ketone body metabolism. In: Scriver CR, Beaudet AL, Sly WS, Valle D (eds) Metabolic and Molecular Bases of Inherited Disease, 8th Ed. McGraw-Hill, New York, pp 2327-2356

3. Fukao T, Scriver CR, Kondo N, T2 Collaborative Working Group 2001 The clinical phenotype and outcome of mitochondrial acetoacetyl-CoA thiolase deficiency $(\beta-$ ketothiolase or T2 deficiency) in 26 enzymatically proved and mutation-defined patients. Mol Genet Metab 72:109-114

4. Fukao T, Zhang G-X, Sakura N, Kubo T, Yamaga H, Hazama A, Kohno Y, Matsuo N, Kondo M, Yamaguchi S, Shigematsu Y, Kondo N 2003 The mitochondrial acetoacetyl-CoA thiolase (T2) deficiency in Japanese patients; urinary organic acid and blood acylcarnitine profiles under stable conditions have subtle abnormalities in T2-deficient patients with some residual T2 activity. J Inherit Metab Dis 26:423-431

5. Gibson KM, Lee CF, Kamali V, Sovik O 1992 A coupled assay detecting defects in fibroblast isoleucine degradation distal to enoyl-CoA hydratase: application to 3-oxothiolase deficiency. Clin Chim Acta 205:127-135

6. Renom G, Fontaine M, Rolland MO, Duprey J, Degand PM, Dobbelaere D 2000 A new case of 2-methylacetoacetyl-CoA thiolase deficiency? J Inherit Metab Dis 23:751-753

7. Robinson BH, Sherwood WG, Taylor J, Balfe JW, Mamer OA 1979 Acetoacetyl CoA thiolase deficiency: a cause of severe ketoacidosis in infancy simulating salicylism. J Pediatr 95:228-233

8. Fukao T, Nakamura H, Song XQ, Nakamura K, Orii KE, Kohno Y, Kano M, Yamaguchi S, Hashimoto T, Orii T, Kondo N 1998 Characterization of N93S, I312T, and A333P missense mutations in two Japanese families with mitochondrial acetoacetyl-CoA thiolase deficiency. Hum Mutat 12:245-254 
9. Fukao T, Yamaguchi S, Orii T, Schutgens RB, Osumi T, Hashimoto T 1992 Identification of three mutant alleles of the gene for mitochondrial acetoacetylcoenzyme A thiolase: a complete analysis of two generations of a family with 3-ketothiolase deficiency. J Clin Invest 89:474-479

10. Niwa H, Yamamura K, Miyazaki J 1991 Efficient selection for high-expression transfectants with a novel eukaryotic vector. Gene 108:192-200

11. Fukao T, Yamaguchi S, Wakazono A, Orii T, Hoganson G, Hashimoto T 1994 Identification of a novel exonic mutation at -13 from 5 ' splice site causing exon skipping in a girl with mitochondrial acetoacetyl-coenzyme A thiolase deficiency. J Clin Invest 93:1035-1041

12. Nakamura K, Fukao T, Perez-Cerda C, Luque C, Song XQ, Naiki Y, Kohno Y, Ugarte M, Kondo N 2001 A novel single base substitution $(380 \mathrm{C}>\mathrm{T})$ that activates a 5 bases-downstream cryptic splice-acceptor site within exon 5 in almost al transcripts in the human mitochondrial acetoacetyl-CoA thiolase gene. Mol Genet Metab 72:115-121
13. Fukao T, Nakamura H, Nakamura K, Perez-Cerda C, Baldellou A, Barrionuevo CR, Castello FG, Kohno Y, Ugarte M, Kondo N 2002 Characterization of six mutations in five Spanish patients with mitochondrial acetoacetyl-CoA thiolase deficiency: effects of amino acid substitutions on tertiary structure. Mol Genet Metab 75:235-243

14. Wakazono A, Fukao T, Yamaguchi S, Hori T, Orii T, Lambert M, Mitchell GA, Lee GW, Hashimoto T 1995 Molecular, biochemical, and clinical characterization of mitochondrial acetoacetyl-coenzyme A thiolase deficiency in two further patients. Hum Mutat 5:34-42

15. Middleton B, Bartlett K 1983 The synthesis and characterisation of 2-methylacetoacetyl coenzyme $\mathrm{A}$ and its use in the identification of the site of the defect in 2-methylacetoacetic and 2-methyl-3-hydroxybutyric aciduria. Clin Chim Acta 128:291-305

16. Middleton B, Bartlett K, Romanos A, Gomez Vazquez J, Conde C, Cannon RA Lipson M, Sweetman L, Nyhan WL 1986 3-Ketothiolase deficiency. Eur J Pediatr $144: 586-589$ 